\title{
Energy System Reform Creates Energy Internet Era
}

\author{
Feng Jianghua*, Chen Xiaoli \\ Division of Research \& Development, Beijing Energy-Net Distributed Energy Company Limited, Beijing, China
}

Email address:

jhf@de-china.com (Feng Jianghua)

*Corresponding author

To cite this article:

Feng Jianghua, Chen Xiaoli. Energy System Reform Creates Energy Internet Era. International Journal of Energy and Power Engineering. Vol. 8, No. 2, 2019, pp. 28-34. doi: 10.11648/j.ijepe.20190803.11

Received: June 8, 2019; Accepted: July 15, 2019; Published: July 30, 2019

\begin{abstract}
The start of energy reformation in China has introduced a huge opportunity for the improvement and reorganization of the energy structure. As the reformation of energy system is going further, there are currently different views on the future energy structure and "Internet + energy". In this article, a review is presented on the development history from the smart energy system to Energy Internet at home and abroad. The current status of the development of the Energy Internet is also interpreted. Then authors demonstrate their own understanding on Energy Internet and the importance of energy system reformation. In the future, the energy structure will be consisted of basic Energy Internet and higher levels of Energy Internet, with spirits of more openness, equality, interactivity and sharing. Human oriented is the original point of Energy Internet. Internet will provide tools to optimize all segments of energy system and finally benefits every customer with "best" energy service. More renewable energy is expected to be accommodated in the Energy Internet, with the important assistance from distributed energy on modulating and backup. The role of distributed energy systems will be highlighted for their important function in the future energy structure. As representing advanced productivity, the Energy Internet is expected to solve current energy problems, create a new field of energy service and help with the economic transformation in China.
\end{abstract}

Keywords: Energy Internet, Energy System Reformation, Distributed Energy, Energy Service

\section{Introduction}

On March 15, 2015, the Central Committee of the Communist Party of China and the State Council promulgated the "Several Opinions on Further Deepening the Reform of the Electric Power System" (hereinafter referred as "Electricity Reform Opinion"), which raises the curtain of electricity reform in China that has been set aside for ten years. It is reported that the plan for the reform of oil and gas market will also come up in the second half of 2015. All the messages indicate that the energy reform is coming in China, bringing an energy market with more freedom, equality, wisdom and prosperity and creating a huge space for distributed energy systems and Energy Internet.

Since "internet+" was referred in Prime Minister Keqiang Li's report on March 3, 2015, the concept of "internet+energy" became a hot topic. The top-level design involves National Energy Administration and Ministry of Industry and Information Technology. In June 2015, National Energy Administration officially released "the
Outline of the Plan for Energy Internet" and 12 sub-projects. It is estimated that the outline will be completed in the end of 2015.

The Energy Internet is one of the most important techniques that promotes the development of energy production and consumption. Currently the main difficulties of interpreting Energy Internet lie in the concept of "interdiscipline" and "combining with system reforming". The author's affiliation, Beijing Energy-Net De. Ltd. (hereinafter referred to as "Energy-Net") has committed itself to the development and promotion of advanced technologies for distributed energy for more than a decade, from the initial natural gas distributed energy technology to the later regional smart energy and now Energy Internet. This paper first reviews the history of the development from the smart energy system to the Energy Internet, and then introduces the author's understanding of the Energy Internet and the significance of the energy system reform to the development of the Energy Internet. 


\section{The Development of Intelligent Energy System and Energy Internet}

\subsection{Global Status}

In developed countries e.g. USA, Japan and EU, the reform of energy system has started since the end of $20^{\text {th }}$ century owing to the demand of national security of energy system. Despite of the different energy composition and social status, the directions of energy reform are all towards marketization, cleanness and intelligence. The developing trend of electricity grid is to promote the distributed power sources that incorporate clean and renewable energies, construct individually controllable micro-grids based on distributed power supplies, regional networks and corresponding loads, and finally combine them by smart grid to achieve optimum balance. In the cell architecture theory that was proposed early in Denmark, the microgrids are likened to individual cells. The instability of renewable energy is first digested in cells and then complemented by the large grid [1]. Under the guidance of this concept, the research and technology of microgrid and smart grid have grown by leaps and bounds over the last decade. In the meantime, distributed power and renewable energy have grown tremendously.

Take the United States and Europe as examples. The United States has proposed the application of distributed cogeneration since 1978. By the end of 2012, more than 6,000 distributed energy stations have been built, with the largest installed capacity in the world, exceeding $82 \mathrm{GW}$ (more than $70 \%$ of which is installed by natural gas triple). The national installed capacity of electric power is $6 \%$ to $7 \%$. The population of UK is only about 60 million, but there are more than 1,000 distributed energy stations. The distributed energy is most promoted in Denmark, with $90 \%$ of regional heating provided by cogeneration. In the last 30 years, The GDP of Denmark has doubled with only $7 \%$ increase in energy consumption and $13 \%$ reduction in emissions, which is regarded as "Denmark model" for "economic prosperity and emissions reduction are no longer contradictory". Germany enacted the Renewable Energy Law in 2000 to guide the orderly development of distributed energy including solar energy, wind energy, biomass energy and water energy. By the end of 2014, Germany has maintained the position of the world's largest photovoltaic power generation for 9 consecutive years. The installed capacity of photovoltaic power generation is about $38.2 \mathrm{GW}$, accounting for $21.5 \%$ of the total installed capacity of the country (the highest in the world), and the power generation capacity is $32.8 \mathrm{GWh}$, accounting for about all. $6.3 \%$ of power generation. On June 9, 2014, the instantaneous PV output of Germany exceeded 50\% portion of the total load.

With the development of distributed energy and renewable energy, the technologies of smart grid and micro-grid became more and more mature, and their integration with the Internet became increasingly close. Although the concept of Energy Internet had not been formally proposed, the de facto Energy Internet gradually formed. After the completion of the first phase of the smart grid in 2008 in Boulder, Colorado, more states began trial operation of the smart grid, involving big companies including IBM, Google, Intel, Cisco and GM. IBM has applied its own software and servers to smart grid systems. Cisco focused on network systems that connect meters, converters, digital power plants, and power plants. Google has developed applications that use electricity meters to save electricity bills. In Europe, Germany has established a nationwide sales platform. The number of sellers has reached more than 1,000 at the beginning of 2015, providing more than 9,000 power packages. Some companies are committed to developing new customized packages (such as Industrial electrolytic aluminum package, small city home package, etc.). Some companies provide customers with search and screening services. Such classification has been very detailed.

\subsection{Energy-Net's Promotion of the Smart Energy System in China}

In China, over the past decade, the strong monopoly of the state grid is hard to shake. The traditional idea of building more large power plants is difficult to change. For the landscape of future energy, the industry of distributed energy has been in a relatively independent and arduous exploration.

In 2002, when the industry of distributed energy is fast growing in Europe and America, Ente was established in Beijing. The English name of the company was Beijing Energy-Net De. Ltd., and Energy-Net is short for Energy Internet. Although named as Energy-Net, at that time, the understanding of the combination of energy and the Internet was relatively shallow. At the beginning, it was only hoped to use the Internet to remotely monitor and control distributed energy stations, thereby reducing operating personnel and reducing costs.

In 2004, the US Department of Energy and the National Energy Administration of China proposed a distributed "Energy Park" in the Olympic Village [2]. The proposal combines CCHP (Combined cooling, heating and power), ground source heat pump, photovoltaic technology, energy storage, and distributed energy system technology. The natural gas distributed energy supply system not only achieves efficient energy supply through cascade utilization of energy, but also solves the problem of unstable and discontinuous renewable energy. The concept was very innovative at that time. In 2008, the Beijing South Railway Station energy project with an investment of 70 million RMB introduced the conceptual design of combining natural gas distributed energy supply, rooftop photovoltaic and sewage source heat pump [3]. In 2009, the Swedish Academy of Environmental Sciences and Energy-Net completed a project funded by the European Union to optimize the energy structure of the Beijing Economic and Technological Development Zone (Yizhuang) Eastern District, and jointly proposed the construction of the Energy Group (a complementary distributed energy supply community built by neighboring companies according to their respective use) the Energy Community (a further integration of multiple energy cooperatives into a regional community that can achieve optimal configuration) [4]. Due to the 
monopoly of the state grid on the regional power supply at that time, the government of the development zone is temporarily unable to accept this new concept.

Afterwards, the concepts and technologies of "Energy Group" and "Energy Community" were further deepened and eventually named as "Smart Energy System" [5-6]. This concept and technology are widely used in the energy system planning or feasibility study reports of dozens of regional projects such as Tianjin Zhongxin Ecological City, Qingdao Sino-German Ecological Park, Chengdu Solid City, Guangzhou Zhongxin Knowledge City, etc., but none of them came to reality up to now. The basic concepts and conditions for realizing a smart energy system are "integration of energy systems, structural optimization and high intelligence". Under the current opportunity of energy system reform, breaking the monopoly of the state grid can achieve "integration" and eventually achieve "structural optimization and high intelligence".

In terms of regional energy planning with a new concept, in 2007, the authors fully studied the idea of the US Midwest Balanced Energy Program (BEP) and introduced it to China. Traditional energy planning uses traditional energy production, conversion and utilization to meet future growth in energy demand. The goal of balanced energy planning is not only to meet future energy needs, but also to seek energy-saving and environmentally-optimized solutions, taking into account local energy characteristics. Combined with renewable energy, distributed gas supply of natural gas, and total energy system, it is an important way to resolve the contradiction between energy, environment and economic development. According to this idea, the distributed energy planning for Shanxi Province and Anhui Tongling has been widely recognized, but these plans are difficult to implement due to the old energy system and some other reasons.

In the process of integration with reality, the balanced energy planning method has been continuously improved and developed into an integrated energy planning method. In 2011, it obtained an invention patent - "a system optimized for the overall planning of distributed energy and its optimization method" [7]. Integrated energy planning establishes a physical model based on energy flow network, and adopts multi-objective particle swarm global evolution algorithm to support multi-objective optimization design of distributed energy systems. In the 2012 Sino-German Ecological Park Smart Energy System Planning Program, intelligence was introduced into energy planning, emphasizing the significance of the Internet in energy planning.

At the same time, recently, many institutions and scholars in China have begun to study the technologies such as "micro-network" [8-10] and "smart grid" [11-15]. The concept of the Xinao Group's Ubiquitous Energy Internet was launched after 2010 [16]. Together with the smart energy system [17-18], thse technologies laid the foundation for the development of China's Energy Internet.

The process of developing smart energy systems and regional integrated energy planning methods is an increasingly clear and profound process for understanding the future energy landscape and development direction, but it has not yet been closely integrated with the Internet technology. And for the energy market, the traditional one-way mode that from the production side to the custom side has not been changed. The major consideration of distributed energy supply is still limited to the role in the energy cascade utilization, energy saving and environmental protection. The introduction of the electricity reform may break the power monopoly, and bring the hope of further integrating with the Internet technology and realizing successful application.

\section{The Concept of "Energy Internet"}

\subsection{The Understanding of "Energy Internet"}

Among the many interpretations of the "Energy Internet", we believe that "people-oriented" is the basic starting point. The Internet establishes convenient communication channels between people, between people and the energy system, on their respective energy and environmental needs, as well as possible contributions, achieve optimization for all the aspects of energy structure including energy production, transportation, distribution, storage, and regulation, and eventually provide better energy service for everyone. Strictly speaking, economics is not the only criterion for energy. Some customs are more concerned with environmental protection, safety and convenience. Therefore, "best energy service" should reflect the most accurate definition of people's demand for Energy Internet.

Our description of the Energy Internet is: Energy Internet is the comprehensive use of advanced power electronics technology, information technology and intelligent management technology, with information network, energy network, Internet of Things as the carrier, and high intelligence optimization control software, big data and cloud computing as the technology platform, connecting a large number of distributed power generation devices (including natural gas distributed energy supply, renewable energy, waste heat and residual pressure utilization, etc.), energy storage and peak shaving systems, energy related monitoring and information collection systems, Internet information transmission systems, intelligence electricity, heat and natural gas etc., finally establish a shared network of energy, information and logistics, build an optimum energy system and provide best energy service for everyone.

From the perspective of human body, it is possible to better understand the Energy Internet. The basic unit of the human body is the cell, which can be regarded as each individual. All energy transmission and distribution networks are like blood vessels. The nervous system is the information Internet. The flow network of other substances in the body (such as the digestive system) can be compared to the logistics network. Our stomach is the energy production and transformation system, and the heart is the power of energy transmission. These two functions are often realized in the Energy Internet through distributed energy supply systems. The balance optimization of the system is of course inseparable from our 
brain, and all intelligent control is implemented here. Above the cell is the tissue, the body, and finally the human body.

\subsection{Clarification of Some Misunderstandings}

\subsubsection{Smart Grid is the Energy Internet}

The smart grid is only part of the Energy Internet, not the whole Energy Internet. As an indispensable part of the Energy Internet, the smart grid technology makes the grid safer, more reliable and flexible, and able to accept more diverse power sources (including large-scale intermittent Renewable energy) through the hardware and software configuration of transmission and distribution. In China, the smart grid pays more attention to large-scale power generation terminals, such as large wind power, but not enough attention to small-scale terminal distributed energy supply. With the development of the Energy Internet, the smart grid will have to accept a large number of small-scale terminal distributed energy. Distributed energy is no longer a simple part of the big grid, but a relatively independent, equal, and non-negligible component of the entire grid. The architecture will undergo profound changes.

\subsection{2. “Global Energy Internet” Is the Energy Internet}

The "global Energy Internet" [15] is only part of the "Energy Internet". The Global Energy Internet is to achieve energy interconnection and balance on a global scale, and to fully integrate large-scale renewable energy (such as solar energy in the desert and wind power at sea) to supply energy globally. This is a grand idea that excludes political factors, perhaps in the future it will be partially or fully realized, but in the moment, we believe that more attention should be paid to distributed energy systems that are directly linked to the interests of hundreds of millions of users. Without this system, China and the world's Energy Internet are unrealistic. It is this most basic Energy Internet that has encountered a boycott of the State Grid that likes to talk about the global Energy Internet. The ongoing reform of the power system will open the way for to build an Energy Internet that is led by distributed energy and that will directly benefit hundreds of millions of people.

\subsection{3. "Demand Side Management" Is the Energy Internet}

"Demand side management" is not Energy Internet. This formulation is still a traditional energy structure that flows from large power plants to large power grids and distribution networks. The large-to-small one-way flow of traditional energy structures is mainly for the management of power supply services, not for the mode that meets interactive Energy Internet or the interests of users.

\subsubsection{Energy Internet Is Achieved Through the Collection and Transmission of Energy Load and Equipment Information}

In many Energy Internet models, energy information collection systems only collect and monitor energy load and equipment information. In fact, the Energy Internet system requires more data than this. It should also include a lot of information related to energy use, such as local climatic conditions and weather forecasts, human life and energy habits, production equipment conditions, plant operations, production sustainability, safety level, capacity reserve, corporate culture, energy prices, etc. This massive amount of information can be quickly analyzed by big data and cloud computing technologies, and the analysis results are used for balanced optimization control of the system or feedback to users.

\subsection{The Structure and Operation of Energy Internet}

\subsubsection{The Fundamental of Energy Internet}

The intelligent microgrid distributed on the end user side will become the underlying basic structure of the energy supply system. Being large or small, these microgrids are built in industrial parks, residential areas, commercial areas and even urban areas. Based on natural gas distributed energy stations that stabilize and regulate output energy, combined with energy storage and other peaking systems, the microgrids fully integrate local solar energy, small wind power, heat pumps, and waste heat and residual pressure of the plant to meet the energy demand for heat, power, and natural gas in the region.

The definition of this microgrid generally depends on the distribution level of the area (typically at $110 \mathrm{kV}$ and below) and the economic range of cold, heat or steam networks. Users within the microgrid are not only energy consumers, but also energy producers or regulators, such as rooftop photovoltaic, waste heat and pressure utilization, use of backup facilities or capacity to provide shared services for microgrids. The electric vehicles that are not used during the day and charged in the night can reversely send electricity to the grid to adjust the peak of the power. Through the measurement, statistics and monitoring equipment that are installed in the user end, the intelligent energy network monitors the real-time information of the end capacity, external energy input, energy use, spare capacity, energy storage system, energy trading, economic operation and environmental protection, then transfers the information to the control center viathe Internet, and transmits the optimal configuration commands to the various components by combining big data and cloud computing, etc.

\subsubsection{Higher Level Energy Internet}

The higher level regional energy is built based on the multiple energy microgrids in the same region, combining with external energy systems, regional energy distribution systems, certain capacity, end users and standby and regulation facilities that are not included in the microgrids. The range of the Energy Internet depends on the planning of the regional administrative, commercial and industrial as well as the distribution level of the transmission and distribution network (generally at $220 \mathrm{kV}$ and below) and other factors. In order to achieve optimal allocation of resources and loads in an even larger range, it is necessary to further plan and build Energy Internet at the provincial and municipal levels. The ideas and technologies of Energy Internet can also be used to optimize the national energy 
system. The information interconnection in large regions and across the country can only be realized via Internet technology with the support of modern technologies such as big data and cloud computing.

\subsubsection{Internetization Is the Foundation of "Integration and Intelligence"}

No matter which level of Energy Internet system, we need an optimized structure and a highly intelligent control system. We have proposed energy "integration, structural optimization and intelligence" in the concept of smart energy system. In fact, without Internet, it is impossible to achieve "structural optimization and intelligence". Therefore, the above three factors also need to add an "Internetization".

\subsubsection{Energy Internet Will Complement the Grid, Large-scale Power generation and Renewable energy}

The intelligent microgrid will first deploy as much renewable energy as possible (rooftop photovoltaic, ground source, river water source, sewage source heat pump, etc.), and try to realize self- balance through natural gas distributed energy, energy storage and peak shaving systems, which will not only reduce the burden for the large power grid, but also provide peaking and security protection for the large power grid. And this situation can increase the proportion of renewable energy and facilitate the transformation of the energy structure.

The intelligent transmission grids connect large power plants (coal-fired power plants, wind farms, hydropower stations, pumped storage power stations, etc.) with regional and basic Energy Internet. Through intelligent regulation and control, under the premise of ensuring power security and achieving power balance, more production of renewable energy such as wind power and solar energy can be accepted, and the optimal configuration of the system can be realized at a higher level.

\subsection{Characteristics of the Energy Internet}

The Energy Internet will have the spirit of openness, equality, interaction and sharing of the Internet.

\subsubsection{Openness}

The grid, heat network and natural gas network are more open, and the access of terminal distributed energy, renewable energy and energy storage is no longer restricted. The underlying structure of the micro grid greatly reduces the impact of unstable power supply on the large power grid. The development of the smart grid has greatly improved the capacity of the large power grid to absorb the renewable energy, thus making the large power grid technically fully liberalized. The opening of the natural gas network and the coordinated adjustment of the Energy Internet will more effectively improve the efficiency of natural gas use, stabilize the peak-to-valley difference, and reduce the cost of gas for users. The opening of the heating network will enable the company's waste heat to be effectively utilized, and reduce the heating cost through complementarity.

\subsubsection{Equality}

The traditional energy system is a hierarchical structure of single-directional top-to-bottom flow, while the energy in the Energy Internet can flow in a multi-directional manner, showing a flat structure. With the support of advanced technologies of Energy Internet, terminal micro grids or individuals are both consumers and contributors to the entire system. The participation and voice of the energy market are greatly enhanced, and the energy interests of end consumers will receive unprecedented attention, which extends the huge blue ocean of business such as new energy services.

\subsubsection{Interaction}

On the one hand, important information such as load forecasting, power supply, spare capacity, and energy storage equipment are coordinated between different levels of power grids such as microgrid, regional distribution network, and intelligent transmission grid, to balance the supply and demand and achieve optimal system configuration. On the other hand, unlike traditional power grids, the Internet makes information more transparent and instant. End users can intuitively and clearly understand the operating status of the system, market price information, and their own power consumption through the Internet, and thus easily participate in the energy market, for example buying electricity, proposing personalized energy requirements, purchasing value-added services, feedback energy experience, etc.; the benefits to heating and natural gas users will be similar to those in power supply. Just as Uber provides a platform for connecting users and drivers via the Internet, Energy Internet will connect consumer terminals with energy producers through various interactive platforms such as power trading platforms.

\subsubsection{Sharing}

The current hot car market is an excellent example of the sharing economy. Through the Internet platform such as Uber, the original information asymmetry is broken, so that all kinds of car demand can be satisfied; this sharing economy better meet the demands by mobilizing idle cars (including private cars) and without increasing the total amount of cars. Through the Internet technology, the Energy Internet can also realize the sharing of information and equipment such as load forecasting, spare capacity, and energy storage system. Through the multi-directional flow of information flow and energy flow, it promotes efficient energy utilization and optimal allocation of system resources. For example, under current conditions, in order to ensure the sustainability of production, almost every factory has different sizes of diesel engine spares, thermal boilers, and spare capacity of electricity or heat purchased from electric power or thermal companies. With $20-50 \%$ userage, these devices are idle for most of the time. If a centralized backup system is built through the Energy Internet, or the spare capacity is shared, the demand and idle rate of spare capacity can be greatly reduced. Further, the spare capacity of the plant could be shared with the spare capacity of the regional grid, thereby reducing the need for spare capacity in the regional grid. 
In the United States, 20 years ago, attempts have been made to network various diesel backup units into grid emergency peak shaving. A good example in China is Nanjing Ganghua Gas. In order to reduce the investment in natural gas peaking reserve capacity, Ganghua Gas signed agreements with several local factories to convert their oil-fired boilers into oil-gas boilers. In the winter, when natural gas is tight, diesel is used (still charged with natural gas prices), and this mode of sharing is used to peak the gas. In 2008, Energy-Net also planned a dual-use distributed energy supply system for the data rooms of more than a dozen banks and insurance companies in the Daoxianghu Data Industry Park in Beijing, which can provide diesel emergency backup for each household. It can also realize distributed and efficient supply of electricity and cold, reduce the investment and land occupation of various cooling systems, and save energy costs; however, due to the obstacles of the state grid, it has not been implemented.

\subsection{Energy Internet Is Expected to Solve Current Energy Problems}

At present, there are many problems in China's energy industry. The first is the imbalance of energy development, in many aspects. For example, the peak-to-valley difference between electricity and natural gas keeps on increasing; the peak-to-valley ratio of Beijing's natural gas in 2014 was as high as 10: 1, and that of Shijiazhuang is 7: 1; the curtailment of wind, PV hydro power occurs at the same time of power shortage in large cities and remote areas; new standby power plant are being built while the spare capacity of a large number of scattered factories is in an idle state; adjusting the price of electricity (such as the wet and dry seasons and peak-to-valley adjustment) does not well solve the power imbalance problem. At the same time, the environment problem has to be dealt with. The ratios of clean energy and renewable energy are still low, and the comprehensive utilization efficiency of energy needs to be improved urgently.

Most problems are due to the system. When the energy system is liberalized, the Energy Internet will build a new energy structure, liberate people's ideas, and form new productive forces. Renewable energy will be accommodated from the user side, energy (electricity) balance will be adjusted from the user side, and resource allocation will be optimized from the user side. The micro-to-macro transition will solve the above problems well.

\subsection{Starting from Building a Basic Energy Internet}

Giant enterprises such as the State Grid have done a lot of work in the intelligent transmission and distribution, but following the top-to-bottom concept and model, they rarely interact with consumers and distributed energy supplies, especially the natural gas distributed energy supply. The construction of the Energy Internet should start from the terminal ends, with the pilots of different scales and different characteristics, researching how to realize information monitoring and collection, load forecasting, energy balance, information exchange, resource sharing, and how the micro energy network can be matched with the region grid, the heating network and the natural gas network. In the process of research, the participation and support of individual and energy-using enterprises are expected. Uber spends hundreds of millions to cultivate users' car habits and occupy the market. We can also set up an Energy Internet club, taking some free services or incentives, and providing corresponding measurement, monitoring and statistical equipment, and software platform free of charge. When the users experience better services, they will pay.

\section{Other Thoughts Inspired by the "Energy Internet"}

\subsection{Positioning of Natural Gas Distributed Energy in the Future Energy Structure}

In the process of promoting distributed energy technology for the past 13 years, our initial understanding of natural gas distributed energy is mainly the cascade utilization of energy and contribution to the environment and energy conservation; in the continuous practice, through the establishment of smart energy system technology, we further recognize the role of natural gas distributed energy with interruptible and adjustable characteristics in the smart energy system, especially with renewable energy. In 2013, the authors completed the project "Value Analysis of Distributed Energy in Optimizing China's Energy Structure" funded by the US Energy Foundation, which systematically studied the impact of natural gas distributed energy on China's energy conservation, emission reduction and energy structure adjustment. The role of the energy system has gained a deeper understanding. However, due to the limitation of traditional views, we always regard the distributed energy supply of natural gas as an energy production system that is closer to the user side and thus able to realize the energy cascade utilization. The understanding of the Energy Internet has led to a great transition in our understanding of natural gas distributed energy. Its standby and regulation functions in the system outperform the capacity function. It may generate little power, but its presence allows the system to operate at its best state. This function is expected to become an important economic feature in the future. This understanding will change the design concept of our energy supply system to a certain extent, and we must rethink its positioning in the entire Energy Internet system.

\subsection{Energy Internet Promotes New Energy Service Industry}

In the era of Energy Internet, terminal microgrids or individuals are both energy consumers and producers, and their participation and voice in the energy market will be greatly enhanced. End users have direct demands to reduce energy costs and improve energy security and convenience, which will lead to new energy service industries in the new landscape, such as: evaluating and transforming users' energy systems, designing and building the most suitable 
(micro-network) energy system for users, providing users with advanced intelligent equipment (metering, monitoring, energy storage, regulation), providing users with a variety of personalized energy packages, providing users with optimum energy services based on big data and cloud computing technology, connect energy supply and demand with smart home appliances through the Internet, and construct a comprehensive smart home life system, provide users with comprehensive consulting services, etc. In addition, it is worth mentioning that It is an interactive network platform for users to understand and participate in the energy market, such as adding their own backup, emergency equipment or capacity to the Energy Internet sharing system, adjusting the working time or way to contribute to the Energy Internet peaking and get rewards. The liberalization of the energy system and the development of energy technology have enabled the formation of a new energy landscape; the development of Internet technology has enabled the individual's status to be improved, and it has become possible to provide individualized energy services for everyone. The long tail effect of the Internet will surely lead to a huge commercial blue ocean of new energy services. Professional energy service companies and energy sales companies (electricity, heat, natural gas) combined with the energy Internet will become new market giants in the future.

\section{Concluding Remarks}

In today's China, the old energy system has severely hampered the development of productivity. The energy reformation in China introduced a huge opportunity for the improvement and reorganization of the energy structure. Under the joint action of society, economy and technology, energy system reform is possible to be implemented. Many people, who are interested in developing distributed energy and promoting energy reform have passed many years of "struggles of repeated defeats and repeated defeats", have finally ushered in a turning point and hope. Especially, the role of the distributed energy system will be highlighted in future energy structure in China, for their important function of adopting renewable energies. Representing the advanced productivity and the future energy structure under the new situation, the Energy Internet will surely become a major driving force for China's economic transformation and social progress.

\section{References}

[1] Angelo L'Abbate, Gianluca Fulli, etc. Distributed Power Generation in Europe: technical issues for further integration [R]. JRC Scientific and Technical Reports. 2007.
[2] FENG Jianghua. The Important Role of Natural Gas in Establishing an Energy Commune in China [J]. Shanghai Electric Power. 2009 (3), pp. 182-187.

[3] HUANG Baomin, Zhu Jianzhang. Discussion of CCHP System in Beijing South Railway Station [J]. Heating Ventilating \& Air Conditioning. 2010 (5).

[4] Beijing Energy-Net De. Ltd., Swedish Academy of Environmental Sciences. Feasibility Study on Energy Structure Optimization of Eastern District of Beijing Economic and Technological Development Zone [R]. China-EU Energy Environment Project Report. 2009.

[5] JEREMY Rifkin. The Third Revolution of Science and Technology [M]. Translated by ZHANG Linwei. Beijing: China CITIC Press. 2012.

[6] HUA Ben. Regarding Natural Gas Power, CHP \& CCHP at the Strategic Height [J]. Energy Construction. 2015, 2 (2), pp. 1-8.

[7] FENG Jianghua, WANG Qinghuan, REN Junjie. A Distributed Energy Overall Planning Optimization System and Optimization Method: CN102073272A [P]. 2011-05-25.

[8] ZHAO Bao, LI Peng. Survey on Development from Distributed Generation to Micro grid [J]. Zhejiang Electric Power, 2010 (3), pp. 1-5.

[9] GUO Jiahuan. Research on Optimization of Microgrid Economic Operation [D]. Beijing: North China Electric Power University, 2010.

[10] MA Li. The Research on the Operation Characteristic of CCHP and Micro Grid Composed of CCHP [D]. Tianjin: Tianjin University, 2008.

[11] LI Naihu, NI Yixin, etc. Survey on Smart Grid and Relevant Key Technologies [J]. Southern Power System Technology, 2010, 4 (3), pp. 1-7.

[12] LIU Zhenya. Smart Grid Technology [M]. Beijing: China Electric Power Press, 2010, pp1-11.

[13] SONG Xuankun, HAN Liu, etc. A R eview on Development Practice of Smart Grid Technology in China [J]. Electric Power Construction, 2016, 37 (7), pp. 1-11.

[14] TONG Guangyi, WANG Mengzhen, etc. Some Ideas on the Development Mode of Smart Grid [J]. South Energy Construction, 2018, 5 (4), pp. 21-28.

[15] LIU Zhenya. Global Energy Internet [M]. Beijing: China Electric Power Press, 2015.

[16] GAN Zhongxue, ZHU Xiaojun, etc. Ubiquitous Energy Internet-New Energy Internet Coupling with Information and Energy [J]. Strategic Study of CAE, 2015, 17 (9), pp. 98-104.

[17] GUO Yongwei, CHENG Aonan. "Internet +" Wisdom Energy: The Development Direction of Future Energy [J]. On Economic Problems, 2015 (11), pp. 61-64.

[18] NIU Zhewen, GUO Caishan, etc. Technical features and development path of "internet + smart energy" [J]. Power Systems and Big Data, 2019, 22 (5), pp. 6-10. 